\title{
PROPRIEDADES FÍSICAS DE SEMENTES DE FEIJÃO EM FUNÇÃO DE TEORES DE ÁGUA
}

Flívia Fernandes de Jesus ${ }^{1}$, Raniele Tadeu Guimarães de Souza ${ }^{2}$, Gisele Carneiro da Silva Teixeira ${ }^{3}$, Itamar Rosa Teixeira ${ }^{4}$, Ivano Alessandro Devilla ${ }^{5}$

\section{RESUMO}

Como as características físicas dos produtos são alteradas pelo processo de secagem, é indispensável o estudo das propriedades físicas dos produtos agrícolas durante este processo, pois tais alterações podem influenciar no dimensionamento de equipamentos e sistemas para colheita, manuseio, transporte, secagem, beneficiamento e armazenamento. Dessa forma, este trabalho objetivou determinar as propriedades físicas de sementes provenientes de cultivares de feijão-comum lançadas recentemente, submetidas a diferentes teores de água. Empregou-se o delineamento inteiramente casualizado, em esquema fatorial $2 \times 5$, com quatro repetições. Os tratamentos foram constituídos de semente provenientes de duas cultivares de feijão (Valente e Pontal), submetidas a cinco teores de água (10, 12, 14, 16 e $18 \%$ b.u.). Conclui-se que as medidas dos eixos ortogonais das sementes ("a", "b" e "c") pertencentes às cultivares de feijão Valente e Pontal, os valores de área projetada e diâmetro geométrico foram influenciadas diretamente pelos teores de água, diminuindo seus valores com o decréscimo do teor de água. Já os valores da esfericidade e da circularidade comportaram de maneira distinta, com aumento destas propriedades para sementes da cultivar Valente e decréscimo para a cultivar Pontal, em função da diminuição do teor de água de 18 para $10 \%$ (b.u.). Os valores de massa específica aparente e massa específica real das sementes de feijão foram inversamente proporcionais aos teores de água, ou seja, aumentaram seus valores com a redução do teor de água.

Palavras-chave: Phaseolus vulgaris, porosidade, massa especifica, classificação de sementes

\section{ABSTRACT \\ PHYSICAL PROPERTIES OF COMMON BEAN SEEDS ACCORDING TO LEVELS OF WATER}

Once the physical characteristics of the products are modified by drying, it is essential the study of the physical properties of agricultural products during this process, because such changes can influence the sizing of equipment and systems for harvesting, handling, transportation, drying, processing and storage. Thus, this study aimed to determine the seeds physical properties from two cultivars of common bean (Valente and Pontal) for different water contents $(10,12,14,16$ and $18 \%$ water content). It was used completely randomized design, factorial scheme $2 \times 5$, with four replications. It was concluded that the measurements of orthogonal axes of seeds ("a", "b" and "c") belonging to the common bean cultivars Valente and Pontal, the values of projected area and geometric diameter were directly influenced by water content, decreasing the values with decreasing water content. However values of sphericity and circularity have different proceeding, increasing these proprieties for the cultivar seed Valente and decreasing for Pontal, due to the decrease of water content from 18 to $10 \%$ (b.u.).The values of bulk density and real density of common bean seeds were inversely proportional to the water content or in other words increasing their values with the reduction of water content.

keywords: Phaseolus vulgaris, porosity, bulk density, classification of seeds

\section{Recebido para publicação em 28/09/2012. Aprovado em 13/11/2012.}

1- Engenheiro Agrônomo, Mestranda em Engenharia Agrícola, UEG/UnUCET, Anápolis-GO, fliviafdejesus@gmail.com

2- Engenheiro Agrônomo, Mestrando em Engenharia Agrícola, UEG/UnUCET, Anápolis-GO, raniele.souza1@gmail.com

3- Engenheiro Agrônomo, Doutoranda em Água e Solos, UFG. Goiânia-GO, email: gisele.agronomia@hotmail.com

4- Engenheiro Agrônomo, Professor Adjunto do Curso de Engenharia da UEG/UnUCET, Anápolis-GO, itamar.texeira@ueg.br

5- Engenheiro Agrícola, Professor Adjunto do Curso de Engenharia da UEG/UnUCET, Anápolis-GO, devilla@ueg.br 


\section{INTRODUÇ̃̃O}

O consumo de feijão tem destaque principalmente nos países em desenvolvimento, das regiões tropicais e subtropicais. Seu baixo custo e suas propriedades nutricionais fazem com que esta fabacea ocupe uma posição de destaque na alimentação humana. Juntamente com o arroz constitui-se importante na base alimentar em alguns países, substituindo em alguns casos a carne e outros produtos proteicos (FERNANDES; SILVEIRA FILHO, 2001; RIOS et al., 2003).

O Brasil configura-se atualmente como o segundo maior produtor mundial de feijão, se considerar todas as espécies do gênero Phaseolus e destaca-se também como o primeiro produtor mundial de feijão-comum, pertencente à espécie P. vulgaris (VIEIRA et al., 2006). Apesar da importância econômica e social inquestionável do feijoeiro no Brasil, o seu rendimento médio pode ser considerado aquém do potencial produtivo da cultura, tendo sido obtido na safra 2010/11 apenas $941 \mathrm{~kg} \mathrm{ha}^{-1}$ (CONAB, 2012). A reduzida taxa de utilização de sementes de qualidade, em torno de 13\% (BOTELHO et al., 2010), pode ser apontada como um dos fatores responsáveis por este baixo patamar de rendimento.

A secagem de sementes de feijão é o processo mais utilizado para assegurar sua qualidade e estabilidade, uma vez que as atividades biológicas e físico-químicas que ocorrem durante o armazenamento, diminuem com a redução do teor de água, inibindo também o crescimento de microrganismos e a possibilidade de proliferação de insetos e pragas (RESENDE et al., 2008). Em adição, diminui o processo respiratório das sementes, mantendo as reservas durante a armazenagem (CARVALHO \& NAKAGAWA, 2000).

Estudos investigativos abordando os temas transferência de calor e massa e a movimentação do ar de secagem requerem informações referentes a propriedades físicas de produtos vegetais. Neste contexto, existem vários estudos na literatura referentes a variação de propriedades físicas de produtos agrícolas, a exemplo de sementes (RESENDE et al., 2005, 2008; RIBEIRO et al.,
2005; RAZAVI et al., 2007a,b), que dizem respeito a forma e concentração volumétrica, durante a realização do processo de secagem.

A alteração do teor de água das sementes, durante a secagem, reduz seu volume e influencia diretamente suas propriedades físicas (KOÇ et al., 2008). Desta forma, determinações destas são necessárias em projetos de engenharia para o desenvolvimento e aperfeiçoamento de máquinas e equipamentos presentes na cadeia produtiva agrícola, especialmente as propriedades geométricas (RESENDE et al., 2008; GONELI et al., 2011). Neste contexto, informações sobre tamanho, volume, porosidade e massa específica, dentre outras características apresentadas por produtos vegetais são tidos de grande relevância para estudos investigativos sobre transferência de calor e massa e movimentação do ar em massas granulares.

A contração volumétrica dos produtos agrícolas durante a secagem ocorre de maneira heterogênea (KHRAISHEH et al., 2004). No início da secagem, aparentemente, o produto permanece com a estrutura intacta e mantém sua forma original. Contudo, com a retirada de água, acontece o seu encolhimento que é acompanhado de deformação das partículas, formação de poros e demais mudanças microestruturais (KOÇ et al., 2008). Ademais, em razão da variabilidade existente nas propriedades físicas de sementes e grãos de cultivares de feijão, associado à necessidade de disponibilizar dados para dimensionamento e aperfeiçoamento de máquinas para a semeadura, colheita e pós-colheita, incluindo as fases de secagem, beneficiamento e acondicionamento, faz necessário a busca destes tipos de informações.

Objetivou com este trabalho avaliar as propriedades físicas das sementes de cultivares de feijão lançadas recentemente, BRS Valente grupo preto e BRS Pontal - carioca, submetidas a diferentes teores de água.

\section{MATERIAL E MÉTODOS}

No experimento foram utilizadas sementes de duas cultivares de feijão, produzidas na safra das águas de 2009/10 na Estação Experimental 
da EMATER em Anápolis-GO. As sementes foram colhidas e descascadas manualmente, e para evitar danos mecânicos, foram transportadas em sacos plástico ao Laboratório de Secagem e Armazenamento de Produtos Vegetais, da Universidade Estadual de Goiás, UnUCET.

Empregou-se o delineamento experimental inteiramente casualizado, em esquema fatorial 2 x 5 , com quatro repetições. Os tratamentos foram compostos pelas duas cultivares de feijão (BRS Valente - grupo preto e BRS Pontal - carioca), submetidas a diferentes teores de água $(10,12,14$, 16 e $18 \%$ base úmida - b.u). A secagem das sementes foi conduzida em um secador experimental, com três bandejas circulares de fundo telado (Figura 1), a temperatura de $35 \pm 3{ }^{\circ} \mathrm{C}$. Inicialmente, foi determinada a massa da amostra a sofrer secagem. A partir da umidade final desejada, determinou-se a quantidade de água a ser retirada das sementes. A secagem foi interrompida quando o peso desejado final foi alcançado.
$\mathrm{O}$ teor de água das sementes foi determinado pelo método padrão de estufa, a $105 \pm 3^{\circ} \mathrm{C}$, durante 24 horas, em três repetições, utilizando balança de precisão de $0,001 \mathrm{~g}$, segundo metodologia da Regra para Análise de Sementes - RAS (BRASIL, 2009). Após secagem, as sementes foram homogeneizadas e encaminhadas para a determinação de suas propriedades físicas.

O tamanho e a forma das sementes de feijão, considerados esferóides oblatos, foram analisados quanto ao comprimento, largura, espessura (Figura 2), esfericidade, circularidade, área projetada e diâmetro geométrico, usando quatro repetições de 50 sementes cada, obtidas por meio de paquímetro digital com resolução de $0,01 \mathrm{~mm}$.

em que

$\mathrm{a}=$ comprimento ou maior eixo, $\mathrm{mm}$;

$\mathrm{b}=$ largura ou eixo médio, $\mathrm{mm}$;

$\mathrm{c}=$ espessura ou menor eixo, $\mathrm{mm}$.

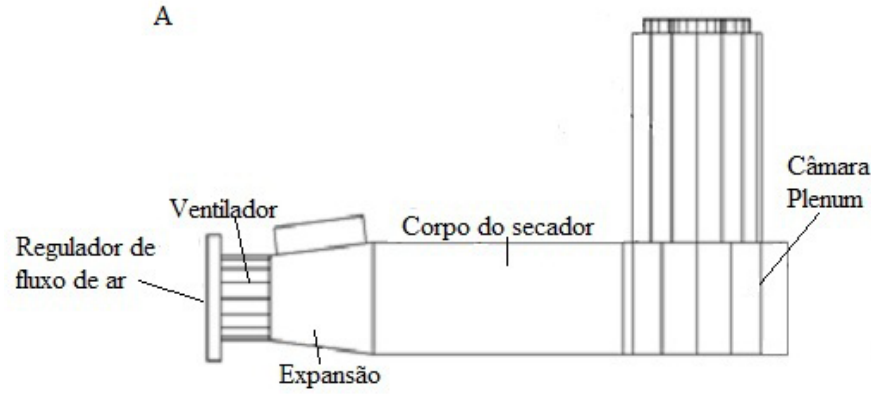

B

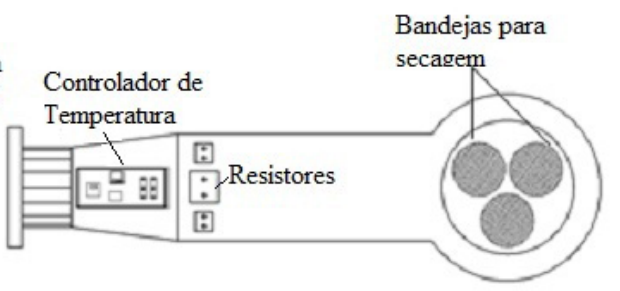

Figura 1. Esquema representativo do secador experimental de leito fixo utilizado na secagem de sementes de feijão: vista lateral (A) e vista superior (B).
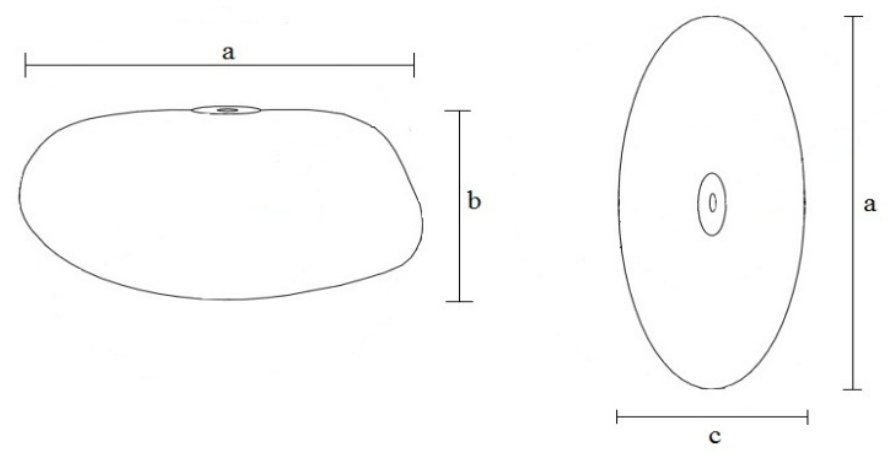

Figura 2. Desenho esquemático da semente de feijão, considerado como esferóide ablato. Fonte: Resende et al. (2005). 
A esfericidade $\left(E_{S}\right)$ das sementes de feijão, expressa em porcentagem, foi calculada utilizandose a equação (1), proposta por Mohsenin (1986):

$$
E_{S}=\left[\frac{(a . b \cdot c)^{\frac{1}{3}}}{a}\right] \cdot 100
$$

A área projetada $(A p)$, expressa $\mathrm{em} \mathrm{mm}^{2}$, das sementes de feijão foi determinada utilizando-se a equação (2):

$$
\mathrm{Ap}=\frac{\pi \cdot a \cdot b}{4}
$$

A circularidade $(C)$ das sementes de feijão foi determinada, em porcentagem, utilizando-se a equação (3), proposta por Mohsenin (1986):

$$
C=\left(\frac{b}{a}\right) \cdot 100
$$

O diâmetro geométrico $\left(D_{G}\right)$, em $\mathrm{mm}^{2}$, das sementes de feijão foi determinado utilizando-se a equação (4), proposta por Mohsenin (1986):

$$
D_{G}=(a . b . c)^{\frac{1}{3}}
$$

A determinação da massa específica aparente $\left(\rho_{a}\right)$, expressa em $\mathrm{kg} \mathrm{m}^{-3}$, foi realizada em quatro repetições, utilizando um equipamento denominado Motomco® (Figura 3) constituído de uma parte, semelhante a um funil, em que o produto é colocado para a determinação, possuindo um dispositivo de acionamento rápido para o escoamento do produto para o recipiente coletor. $\mathrm{O}$ funil possui as seguintes dimensões: diâmetro superior a 19,5 cm; abertura de escoamento $4,5 \mathrm{~cm}$ e altura de $12,5 \mathrm{~cm}$. Distante $5,7 \mathrm{~cm}$ deste funil, a partir da abertura de escoamento está um recipiente coletor de volume igual a 222,8 mL, de seção circular de $5,4 \mathrm{~cm}$ de diâmetro e altura de $9,8 \mathrm{~cm}$.

Esse recipiente foi tarado na balança analítica de precisão $0,001 \mathrm{~g} \mathrm{e}$, imediatamente, recebeu os grãos até o seu completo preenchimento. Com um nivelador foi retirado o excesso de produto existente, e o mesmo novamente foi pesado na mesma balança. A massa específica aparente do produto foi obtida utilizando-se a a equação (5):

$$
\rho_{a}=\frac{m}{v}
$$

em que

$\rho_{a}=$ massa específica aparente, $\mathrm{kg} \mathrm{m}^{-3}$;

$m=$ massa das sementes, $\mathrm{kg}$; e

$v=$ volume do recipiente, $\mathrm{m}^{3}$.

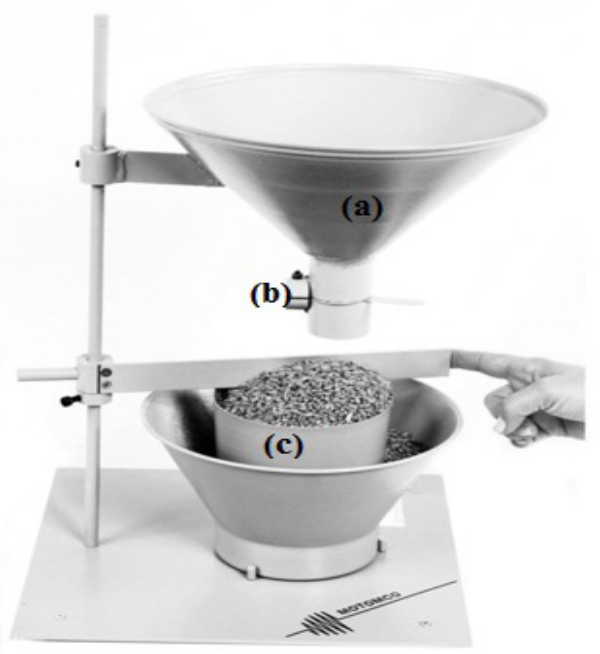

Figura 3. Dispositivo Motomco ${ }^{\circledR}$ para determinação da massa específica aparente: (a) recipiente para colocação do produto, (b) dispositivo de acionamento e (c) recipiente coletor. Fonte: Motomco (2012).

A determinação da porosidade intergranular $(\varepsilon)$, expressa em porcentagem (\%), das sementes de feijão foi feita pelo método direto de complementação do volume (MOHSENIN, 1986). Em uma vidraria de $120 \mathrm{~mL}$ o produto foi escoado para o seu interior, com o mesmo método adotado anteriormente, e com auxilio de uma bureta de 50 $\mathrm{mL}$ foi acrescido óleo de soja até o preenchimento de todos os espaços vazios. Em seguida, foi realizada a leitura da bureta para determinar a quantidade de óleo de soja utilizada e consequentemente a volume dos vazios na massa de sementes.

A massa específica real ou unitária $\left(\rho_{u}\right)$, expressa 
em kg.m ${ }^{-3}$, foi obtida em função da porosidade $(\varepsilon)$ e da massa específica aparente $\left(\rho_{a}\right)$, de acordo com a equação (6) descrita por Mohsenin (1986):

$$
\rho_{u}=\frac{\rho_{a}}{(1-\varepsilon)}
$$

Os dados obtidos foram submetidos à análise de variância, e quando pertinente foi empregado o teste de Tukey, a $5 \%$ de probabilidade, utilizando o programa Sisvar Versão 5.3.

\section{RESULTADOS E DISCUSSÃO}

Houve redução dos três eixos ortogonais das sementes da cultivar Valente, sendo que estes decréscimos foram respectivamente de 6,21;4,30 e $4,30 \%$, para os eixos maior, médio e menor, em relação às suas dimensões iniciais, com a redução do teor de água de 18 até 10\% (b.u.) (Quadro 1). Comportamento idêntico foi notado para cultivar Pontal, porém, com reduções de 3,18; 3,95 e $4,23 \%$ dos eixos ortogonais (Quadro 2). Neste contexto, pode-se notar que as sementes de feijão das duas cultivares, semelhantemente a maioria dos produtos biológicos, contraem-se de forma irregular nas diversas direções com a secagem, conforme constatado em outros trabalhos de pesquisa (RUFFATO et al., 1999; CORRÊA et al., 2002; RESENDE et al., 2005, 2008; GONELI et al., 2011).

Os valores da área projetada e do diâmetro geométrico decresceram com a redução do teor de água de 18 para $10 \%$ (b.u.) para as duas cultivares analisadas. Já os valores da esfericidade e da circularidade se comportaram de forma distinta

Quadro 1. Dimensões médias dos eixos ortogonais ("a", "b" e "c"), esfericidade $\left(\mathrm{E}_{\mathrm{S}}\right)$, circularidade $(\mathrm{C})$, área projetada $(\mathrm{Ap})$ e diâmetro geométrico $\left(\mathrm{D}_{\mathrm{G}}\right)$ das sementes de feijão-comum cv. BRS Valente, submetidas à diferentes teores de água

\begin{tabular}{|c|c|c|c|c|c|c|c|}
\hline \multirow{2}{*}{$\begin{array}{l}\text { Teor de água } \\
\text { (\% b.u.) }\end{array}$} & \multicolumn{3}{|c|}{ Eixos ortogonais (mm) } & \multirow{2}{*}{$\begin{array}{c}E_{S} \\
(\%) \\
-\end{array}$} & \multirow{2}{*}{$\begin{array}{c}\mathrm{C} \\
(\%) \\
- \\
\end{array}$} & \multirow{2}{*}{$\begin{array}{c}\text { Ap } \\
\left(\mathrm{mm}^{2}\right) \\
-\end{array}$} & \multirow{2}{*}{$\begin{array}{c}\mathrm{D}_{\mathrm{G}} \\
(\mathrm{mm}) \\
-\end{array}$} \\
\hline & A & $\mathrm{b}$ & $\mathrm{C}$ & & & & \\
\hline 18 & 9,98 a* & $6,75 \mathrm{a}$ & $5,12 \mathrm{a}$ & $70,30 \mathrm{~b}$ & $67,71 \mathrm{~b}$ & $52,98 \mathrm{a}$ & $7,01 \mathrm{a}$ \\
\hline 16 & $9,68 \mathrm{ab}$ & $6,66 \mathrm{ab}$ & $5,09 \mathrm{ab}$ & $71,28 \mathrm{a}$ & 68,95 a & $50,78 \mathrm{ab}$ & $6,89 a b$ \\
\hline 14 & $9,58 \mathrm{~b}$ & $6,58 \mathrm{~b}$ & $5,01 \mathrm{~b}$ & $71,10 \mathrm{ab}$ & $68,73 \mathrm{ab}$ & $49,57 \mathrm{~b}$ & $6,80 \mathrm{~b}$ \\
\hline 12 & $9,58 \mathrm{~b}$ & $6,54 \mathrm{~b}$ & $5,09 \mathrm{ab}$ & $71,32 \mathrm{a}$ & $68,30 \mathrm{ab}$ & $49,29 \mathrm{~b}$ & $6,83 \mathrm{~b}$ \\
\hline 10 & $9,36 \mathrm{c}$ & $6,46 \mathrm{c}$ & $4,90 \mathrm{~b}$ & $71,23 \mathrm{ab}$ & $69,10 \mathrm{a}$ & $47,64 \mathrm{c}$ & $6,66 \mathrm{c}$ \\
\hline
\end{tabular}

*Médias seguidas pela mesma letra na coluna, não diferem estatisticamente entre si, pelo teste de Tukey, em nível de $5 \%$ de probabilidade.

Quadro 2. Dimensões médias dos eixos ortogonais ("a", "b" e "c"), esfericidade $\left(E_{s}\right)$ circularidade $(C)$, área projetada $(\mathrm{Ap})$ e diâmetro geométrico $\left(\mathrm{D}_{\mathrm{G}}\right)$ das sementes de feijão-comum cv. BRS Pontal, submetidas à diferentes teores de água

\begin{tabular}{|c|c|c|c|c|c|c|c|}
\hline \multirow{2}{*}{$\begin{array}{l}\text { Teor de água } \\
\text { (\% b.u.) }\end{array}$} & \multicolumn{3}{|c|}{ Eixos ortogonais (mm) } & \multirow{2}{*}{$\begin{array}{c}\mathrm{E}_{\mathrm{S}} \\
(\%) \\
- \\
\end{array}$} & \multirow{2}{*}{$\begin{array}{l}\text { C } \\
(\%) \\
-\end{array}$} & \multirow{2}{*}{$\begin{array}{c}\mathrm{Ap} \\
\left(\mathrm{mm}^{2}\right) \\
- \\
\end{array}$} & \multirow{2}{*}{$\begin{array}{c}\mathrm{D}_{\mathrm{G}} \\
(\mathrm{mm}) \\
-\end{array}$} \\
\hline & A & $\mathrm{b}$ & $\mathrm{c}$ & & & & \\
\hline 18 & $10,37 a^{*}$ & $6,84 \mathrm{a}$ & $4,73 \mathrm{a}$ & $67,03 \mathrm{a}$ & $66,10 \mathrm{a}$ & $55,78 \mathrm{a}$ & $6,94 \mathrm{a}$ \\
\hline 16 & $10,20 \mathrm{~b}$ & $6,69 \mathrm{ab}$ & $4,66 \mathrm{ab}$ & $66,98 \mathrm{~b}$ & $65,77 \mathrm{~b}$ & $53,70 \mathrm{ab}$ & $6,82 \mathrm{ab}$ \\
\hline 14 & $10,19 \mathrm{~b}$ & $6,62 \mathrm{~b}$ & $4,60 \mathrm{~b}$ & $66,44 \mathrm{~b}$ & $65,06 \mathrm{~b}$ & $53,08 \mathrm{~b}$ & $6,76 \mathrm{~b}$ \\
\hline 12 & $10,05 \mathrm{c}$ & $6,61 \mathrm{~b}$ & $4,58 \mathrm{~b}$ & $66,96 \mathrm{~b}$ & $65,99 \mathrm{~b}$ & $52,28 \mathrm{~b}$ & $6,72 \mathrm{~b}$ \\
\hline 10 & $10,04 \mathrm{c}$ & $6,57 \mathrm{c}$ & $4,55 \mathrm{c}$ & $66,72 \mathrm{~b}$ & $65,65 \mathrm{~b}$ & $51,94 \mathrm{c}$ & $6,69 \mathrm{c}$ \\
\hline
\end{tabular}

*Médias seguidas pela mesma letra na coluna, não diferem estatisticamente entre si, pelo teste de Tukey, em nível de $5 \%$ de probabilidade. 
para as duas cultivares. Na cv. Valente com a diminuição do teor de água de 18 para $10 \%$ (b.u.) ocorreu o aumento dessas propriedades. Resende et al. (2005) observaram comportamento semelhante no estudo de feijão vermelho durante processo de secagem. Porém, na cultivar Pontal ocorreu à diminuição dessas propriedades com a diminuição dos teores de água, fato também observado por Corrêa et al. (2002) no estudo de frutos de café durante processo de secagem. Esse fenômeno distinto entre as duas cultivares pode ser explicado devido à contração no eixo maior ("a") ter sido superior aos demais eixos na cultivar. Valente, ao contrário da cultivar Pontal em que o eixo maior ("a") obteve a menor contração, já que este parâmetro é um fator inversamente proporcional a circularidade e a esfericidade.

Houve efeito significativo dos tratamentos sobre a massa específica aparente das sementes nas duas cultivares em relação aos diferentes teores de água (Quadro 3). Em contrapartida, não foi notado qualquer efeito significativo da massa especifica aparente de sementes e da interação dupla cultivares x teores de água (Quadro 4). Em relação aos teores de água, verifica-se que a massa específica aparente apresentou maior valor para o teor de água de $10 \%$ (b.u.) e o menor valor para o teor de água de $18 \%$ (b.u.), comprovando o decréscimo desta propriedade com o aumento do teor de água, comportamento semelhante encontrado na maioria dos produtos agrícolas pesquisados: milho-pipoca (RUFFATO et al., 1999), sementes de mamão (CARLESSO et al., 2005), soja (RIBEIRO et al., 2005), trigo (CORRÊA et al., 2006) e feijão do grupo vermelho (RESENDE et al., 2008). Para Carlesso et al. (2005), a redução no valor da massa específica aparente com o aumento do teor de água nas sementes demonstra que o aumento da massa da amostra em função do acréscimo da massa de água foi proporcionalmente menor que sua correspondente expansão volumétrica.

Quadro 3. Análise de variância da massa específica aparente, para sementes de cultivares de feijão, submetidas a diferentes teores de água

\begin{tabular}{lcccc}
\hline Fonte de Variação & G. L. & S. Q. & Q. M. & F \\
\hline Cultivar (A) & 1 & 3,36400 & 3,36400 & $0,237^{\text {ns }}$ \\
Teores de Água (B) & 4 & 1692,10458 & 423,02615 & $29,837^{*}$ \\
(A) x (B) & 4 & 144,97793 & 36,24448 & $2,5556^{\text {ns }}$ \\
Resíduo & 30 & 425,33660 & 14,17789 & - \\
\hline Total & 39 & 2265,78311 & - & - \\
\hline
\end{tabular}

* = significativo em nível de $5 \%$ de probabilidade; ns = não significativo.

Quadro 4. Comparação entre os valores médios da massa específica aparente, para sementes de cultivares submetidas a diferentes teores de água

\begin{tabular}{cc}
\hline Cultivar & Massa Especifica Aparente $\left(\mathrm{kg} \mathrm{m}^{-3}\right)$ \\
\hline BRS Valente & $748,44 \mathrm{a}^{*}$ \\
BRS Pontal & $747,86 \mathrm{a}$ \\
\hline Teor de Água (\% b.u.) & - \\
\hline 10 & $757,06 \mathrm{a}$ \\
12 & $752,36 \mathrm{ab}$ \\
14 & $749,38 \mathrm{~b}$ \\
16 & $743,33 \mathrm{c}$ \\
18 & $738,66 \mathrm{c}$ \\
\hline Média & 748,16
\end{tabular}

*Médias seguidas pela mesma letra na coluna, não diferem estatisticamente entre si, pelo teste de Tukey, em nível de $5 \%$ de probabilidade.

\section{REVENG} 09-18p. 
O valor da porosidade da cultivar Pontal foi ligeiramente superior ao da cultivar Valente, não diferindo, porém entre si estatisticamente (Quadro 5). Houve acréscimo da porosidade com o aumento do teor de água nas sementes, com o maior valor, $42,29 \%$, obtido com o teor de água de $18 \%$ (b.u.). Os demais valores não se diferem estatisticamente entre si (Quadro 6). Resende et al. (2008) estudando as propriedades físicas de grãos de feijão do grupo vermelho, obtiveram valores de porosidade entre 38,3 e $44,1 \%$ para a faixa de teor de água entre 10 a $30 \%$ (b.u.).

Constatou-se a ocorrência de diferença significativa tanto para as cultivares de feijão quanto para os teores de água no tocante à massa específica real, porém não houve significância da interação entre as duas variáveis analisadas (Quadro 7).

Quadro 5. Análise de variância da porosidade, para sementes de cultivares de feijão, submetidas diferentes teores de água

\begin{tabular}{ccccc}
\hline Fonte de Variação & G. L. & S. Q. & Q. M. & F \\
\hline Cultivar (A) & 1 & 0,32942 & 0,32942 & $0,211 \mathrm{~ns}$ \\
Teores de Água (B) & 4 & 44,60799 & 11,15200 & $7,151^{*}$ \\
(A) x (B) & 4 & 9,80974 & 2,45435 & $1,573 \mathrm{~ns}$ \\
Resíduo & 30 & 46,78723 & 1,55957 & - \\
\hline Total & 39 & 101,53438 & - & - \\
\hline
\end{tabular}

* = significativo em nível de $5 \%$ de probabilidade; ns = não significativo.

Quadro 6. Comparação entre os valores médios da porosidade, para sementes de cultivares de feijão, submetidas a diferentes teores de água

\begin{tabular}{cc}
\hline Cultivar & Porosidade (\%) \\
\hline BRS Valente & $40,19 \mathrm{a}^{*}$ \\
BRS Pontal & $40,37 \mathrm{a}$ \\
\hline Teor de Água (\% b.u.) & - \\
\hline 10 & $39,41 \mathrm{~b}$ \\
12 & $39,63 \mathrm{~b}$ \\
14 & $39,69 \mathrm{~b}$ \\
16 & $40,39 \mathrm{~b}$ \\
18 & $42,29 \mathrm{a}$ \\
\hline Média & 40,28 \\
\hline
\end{tabular}

*Médias seguidas pela mesma letra na coluna, não diferem estatisticamente entre si, pelo teste de Tukey, em nível de $5 \%$ de probabilidade.

Quadro 7. Análise de variância da massa específica real, para sementes de cultivares, submetidas a diferentes teores de água

\begin{tabular}{ccccc}
\hline Fonte de Variação & G. L. & S. Q. & Q. M. & F \\
\hline Cultivar (A) & 1 & 1233,32130 & 1233,32130 & $13,398^{*}$ \\
Teores de Água (B) & 4 & 1090,74947 & 272,68737 & $2,962^{*}$ \\
(A) x (B) & 4 & 541,94499 & 135,48625 & $1,472^{\mathrm{ns}}$ \\
Resíduo & 30 & 2761,61513 & 92,05384 & - \\
\hline Total & 39 & 5627,63088 & - & - \\
\hline
\end{tabular}

* = significativo em nível de 5\% de probabilidade; ns = não significativo. 
A cultivar Pontal apresentou maior valor médio de massa específica real, sendo igual a $1254,21 \mathrm{~kg} \mathrm{~m}^{-3}$, enquanto para a cultivar Valente foi obtido valor médio de $1243,11 \mathrm{~kg} \mathrm{~m}^{-3}$ (Quadro 8). Dentre os teores de água analisados, o que apresentou maior valor médio foi a $18 \%$ (b.u.) com 1258,13 $\mathrm{kg} \mathrm{m}^{-3}$, enquanto o de menor valor foi encontrado para o teor de água de $14 \%$ (b.u.) com 1242,56 $\mathrm{kg} \mathrm{m}^{-3}$. Resende et al. (2008), estudando feijão vermelho durante processo de secagem obtiveram valores de massa específica real variando de 1361 a $1468 \mathrm{~kg} \mathrm{~m}^{-3}$ para os teores de água de 10 a 30\% (b.u.), valores estes superiores aos encontrados para as duas cultivares neste trabalho.

$\mathrm{Na}$ maioria dos produtos agrícolas estudados, os valores da massa específica real tendem a diminuir, assim como a massa específica aparente, com o aumento do teor de água. Nas duas cultivares analisadas o valor médio da massa específica real seguiu esta tendência com o aumento na faixa do teor de água entre 10 e $14 \%$ (b.u.). Porém se comportou de forma contrária, aumentando seu valor, com o aumento do teor de água de 14 a $18 \%$ (b.u.). Este comportamento está relacionado a um súbito aumento da porosidade da massa de grãos na faixa do teor de água entre 14 e $18 \%$ (b.u.), uma vez que a massa específica real e a porosidade são propriedades diretamente proporcionais e este aumento, proporcionalmente maior que os demais, proporcionando elevação do valor da massa específica real das cultivares nesta faixa de umidade. Ademais, Couto et al. (1999) verificaram em cultivares de café, que em função do teor de umidade para uma faixa comum de umidade de 18,6 a $62,6 \%$ b.u, houve aumento na massa especifica real em relação ao aumento do teor de agua do grão. Nos grãos de trigo o aumento da umidade no intervalo de $03 \%$ a $8 \%$ ocorre ligeiro aumento na massa especifica tanto aparente quanto real (NELSON, 1980).

\section{CONCLUSÕES}

- O decréscimo dos teores de água nas sementes feijão pertencentes às cultivares Valente e Pontal influencia as suas propriedades físicas, com diminuição dos eixos ortogonais, área projetada e diâmetro geométrico. Por outro lado, os valores da esfericidade e da circularidade se comportaram de forma distinta, com aumento destas propriedades para sementes da cultivar Valente e decréscimo para a cultivar Pontal, com a diminuição do teor de água de 18 para $10 \%$ (b.u.); e

- Os valores de massa específica aparente e massa específica real das sementes de feijão são inversamente proporcionais aos teores de água, ou seja, aumentam seus valores com a redução do teor de água.

Quadro 8. Comparação entre os valores médios da massa específica real, para cultivares de feijão, submetidas à diferentes teores de água

\begin{tabular}{cc}
\hline Cultivar & Massa Especifica Real $\left(\mathrm{kg} \mathrm{m}^{-3}\right)$ \\
\hline BRS Valente & $1243,11 \mathrm{~b}^{*}$ \\
BRS Pontal & $1254,21 \mathrm{a}$ \\
\hline Teor de Água (\% b.u.) & - \\
\hline 10 & $1249,43 \mathrm{ab}$ \\
12 & $1246,17 \mathrm{ab}$ \\
14 & $1242,56 \mathrm{~b}$ \\
16 & $1247,01 \mathrm{ab}$ \\
18 & $1258,13 \mathrm{a}$ \\
\hline Média & 1248,66
\end{tabular}

*Médias seguidas pela mesma letra na coluna, não diferem estatisticamente entre si, pelo teste de Tukey, em nível de $5 \%$ de probabilidade.

16 REVENG $09-18 \mathrm{p}$. 


\section{AGRADECIMENTOS}

Os autores agradecem à Capes, pelo auxilio financeiro concedido por meio de bolsa, aos mestrandos do curso de Engenharia Agrícola da Universidade Estadual de Goiás.

\section{REFERÊNCIAS BIBLIOGRÁFICAS}

BOTELHO, F.J.E.; GUIMARÃES, R.M.; OLIVEIRA, J.A.; EVANGELISTA, J.R.E.; ELOI, T.A.; BALIZA, D.P. Desempenho fisiológico de sementes de feijão colhidas em diferentes períodos do desenvolvimento. Ciência e Agrotecnologia, Lavras, v.34, n.4, p.900-907, 2010.

BRASIL. Ministério da Agricultura, Pecuária e Abastecimento. Regras para análise de sementes. Brasília: MAPA/ACS, 2009. 395p.

CARLESSO, V.O.; BEBERT, P.A.; SILVA, R.F.; MOLINA, M.B.; OLIVEIRA, M.T.R. Massa específica aparente de sementes de mamão Carica Papaya L. do cultivar Golden em função do teor de água. Papaya Brasil - II Simpósio do Papaya Brasileiro, Anais...Vitória, p.256-259, 2005.

CARVALHO, N.M.; NACAGAWA, J. Sementes: ciência, tecnologia e produção. Jaboticabal: FUNEP, 2000. 588p.

\section{COMPANHIA}

NACIONAL

DE

ABASTECIMENTO(CONAB). Acompanhamento da safra brasileira: grão: safra 2011/2012, sexto levantamento, março 2011. Disponível em: http://www.conab.gov.br/OlalaCMS/uploads arquivos/12_01_10_10_54_22_boletim_cafe_1a estimativa.pd\$ . Acesso em: 15 mar. 2012.

CORRÊA, P.C.; AFONSO JÚNIOR, P.C.; QUEIROZ, D.M.; SAMPAIO, C.P.; CARDOSO, J.B. Variações das dimensões características e da forma dos frutos de café durante o processo de secagem. Revista Brasileira de Engenharia Agrícola e Ambiental, Campina Grande, v.6, n.3, p.466-470, 2002.

CORRÊA, P.C.; RIBEIRO, D.M. RESENDE, O.;
BOTELHO, F.M. Determinação e modelagem das propriedades físicas e da contração volumétrica do trigo, durante a secagem. Revista Brasileira de Engenharia Agrícola e Ambiental, Campina Grande, v.10, n.3, p.665-670, 2006.

COUTO, S. M; MAGALHÃES, A. C.; QUEIROZ, D. M; BASTOS, I. T.; Massa específica aparente e real e porosidade de grãos de café em função do teor de umidade. Revista Brasileira de Engenharia Agrícola e Ambiental, Campina Grande, v.3, n.1, p.61-68, 1999.

FERNANDES, G.M.B.; SILVEIRA FILHO, B.F. Armazenamento de sementes de feijão na pequena propriedade. Rio de Janeiro: PESAGRO, 2001. 5p.

GONELI,A.L.D.; CORRÊA, P.C.; MAGALHÃES, F.E.A.; BAPTESTINI, F.M. Contração volumétrica e forma dos frutos de mamona durante a secagem. Acta Scientiarum - Agronomia, Maringá, v.33, n.1, p.1-8, 2011.

KHRAISHEH, M.A.M.; MCMINN, W.A.M.; MAGEE, T.R.A. Quality and structural changes in starchy foods during microwave and convective drying. Food Research International, London, v. 34, n.5, p.497-503, 2004.

KOÇ, B.; EREN, I.; ERTEKIN, F.K. Modelling bulk density, porosity and shrinkage of quince during drying: The effect of drying method. Journal of Food Engineering, Amsterdam, v.85, n.3, p.340-349, 2008.

MOHSENIN, N.N. Physical properties of plant and animal materials. New York: Gordon and Breach science publishers Inc., 1986. 734p.

MOTOMCO. Produtos: acessórios - kit para balança. 2012. Disponível em: http://www.motomco. com.br/2012/equipamentos.php?section=7\&equipm ent=KitBalanca. Acesso em: 05 nov. 2012.

NELSON, S.O. Moisture-dependent kernel- and bulk-density relationships for wheat and corn. Transações da ASAE, v.23, n.1, p.139-143, 1980. 
RAZAVI, S.M.A.; EMADZADEH, B.; RAFE, A.; AMINI, A.M. The physical properties of pistachio nut and kernel as a function of moisture content and variety: Part I. Geometrical properties. Journal of Food Engineering, v.81, n.1, p.209-217, 2007a.

RAZAVI, S.M.A.; RAFE, A.; MOGHADDAM, T.M.; AMINI, A.M. The physical properties of pistachio nut and kernel as a function of moisture content and variety: Part II. Gravimetrical properties. Journal of Food Engineering, v.81, n.1, p.218-225, 2007b.

RESENDE, O.; CORRÊA, P.C.; GONELI, A.L.D.; RIBEIRO, D.M. Forma, tamanho e contração volumétrica do feijão (Phaseolus vulgaris L.) durande a secagem. Revista Brasileira de Produtos Agroindustriais, Campina Grande, v.7, n.1, p.15-24, 2005.

RESENDE, O.; CORRÊA, P.C.; GONELI, A.L.D.; RIBEIRO, D.M. Propriedades físicas do feijão durante a secagem: determinação e modelagem. Ciência e Agrotecnologia, Lavras, v.32, n.1, p.225-230, 2008.
RIBEIRO, D.M.; CORRÊA, P.C.; RODRIGUES, D.H.; GONELI, A.L.D. Análise da variação das propriedades físicas dos grãos de soja durante o processo de secagem. Ciência e Tecnologia de Alimentos, Campinas, v.25, n.3, p.611-617, 2005.

RIOS, A.O.; ABREU, C. M. P.; CORREA, A. D. Efeito da estocagem e das condições de colheita sobre algumas propriedades físicas, químicas e nutricionais de três cultivares de feijão (Phaseolus vulgaris, L.). Ciência e Tecnologia de Alimentos, Campinas, v.23, p.39-45, 2003.

RUFFATO, S.; CORREAA, P.C.; MARTINS, J.H.; MANTOVANI, B.H.; SILVA, J.N. Influência do processo de secagem sobre a massa específica aparente, massa específica unitária e porosidade de milho-pipoca. Revista Brasileira de Engenharia Agrícola e Ambiental, Campina Grande, v.3, n.1, p.45-48, 1999.

VIEIRA, C.; PAULA JÚNIOR, T.J.; BORÉM, A. Feijão. $2^{\mathrm{a}}$ ed. atualizada e ampliada. Viçosa: UFV, 2006. 600p. 